\title{
Integrated model-based optimisation at the WWTP of Eindhoven
}

\author{
K. Cierkens ${ }^{\mathrm{a},{ }^{*}}$, I. Nopens ${ }^{\mathrm{a}}$, W. De Keyser ${ }^{\mathrm{a}}$, S. Van Hulle ${ }^{\mathrm{a}, \mathrm{b}}$, S. Plano ${ }^{\mathrm{a}}$, E. Torfs ${ }^{\mathrm{a}}$, Y. Amerlinck ${ }^{\mathrm{a}}$, L. Benedetti ${ }^{\mathrm{c}}$, \\ A. van Nieuwenhuijzen ${ }^{\mathrm{d}, \mathrm{e}}, \mathrm{S}$. Weijers ${ }^{\mathrm{d}}, \mathrm{J}$. De Jonge ${ }^{\mathrm{d}}$ \\ ${ }^{a}$ BIOMATH, Department of Mathematical Modelling, Statistics and Bioinformatics, Ghent University, Coupure \\ Links 653, B-9000, Ghent, Belgium. (E-mail: Katrijn.cierkens@ugent.be, Ingmar.nopens@ugent.be) \\ ${ }^{\mathrm{b}}$ Research Group EnBiChem, Department of Industrial Engineering and Technology, University College West \\ Flanders, Ghent University Association, Graaf Karel de Goedelaan 5, B-8500 Kortrijk, Belgium \\ ${ }^{c}$ WATERWAYS srl, Via del Ferrone 88, 50023 Impruneta (FI), Italy. (E-mail: lorenzobenedetti@ waterways.it) \\ d Waterschap De Dommel, 5280 Boxtel, The Netherlands. (E-mail: AvNieuwenhuijzen@dommel.nl, \\ SWeijers@dommel.nl, JdJonge@dommel.nl) \\ e Witteveen+Bos Consulting Engineers, PO Box 233, NL-7400 AE Deventer, The Netherlands (E-mail: \\ a.vnieuwenhuijzen@witteveenbos.nl) \\ * Corresponding author.
}

\begin{abstract}
The current model of the full-scale wastewater treatment plant model in Eindhoven uses a state-of-the-art model for the biological processes (ASM2d) and is calibrated for C- and N- removal in dry weather. However, for the "Kallisto" project, which is an innovation programme aiming at a smart improvement of the surface water quality of the river Dommel by applying cost effective integrated system measures, the WWTP model needs to be improved to predict the WWTP performance under all conditions foreseen in the scenarios (e.g. storm events). A project approach was developed with parallel improvements in the different submodels, based on the interaction between submodels and the availability of several on-line sensors in influent, in-process and effluent. This is in contrast to most WWTP modelling studies, where focus is only on one submodel. It should lead to a well-balanced dynamic model that is able to predict WWTP behaviour under various conditions and that will be included in the integrated model, which will serve as an important decision support tool.
\end{abstract}

Keywords

urban wastewater system, dynamic modelling, WWTP optimization

\section{INTRODUCTION}

Overall improvement of efficiency, increasingly stringent effluent discharge limits, the aim for a better surface water quality, minimization of energy use and greenhouse gas emissions are current drivers for the optimization of urban wastewater systems and operational strategies of wastewater treatment plants (WWTPs). In this respect, the use of dynamic models has already proven to be of great value. Indeed, a model with high predictive power allows testing of different optimisation strategies without disrupting the actual operation of the plant i.e. without the risk of losing biomass or violating discharge permits. Waterboard De Dommel (WDD, The Netherlands) has shown long-term interest in the development and use of dynamic models, which resulted in a calibrated dynamic model (including COD, $\mathrm{N}$ and $\mathrm{P}$ removal) of WWTP Haaren (Sin et al.,2008). Building further on the gained knowledge, a full-scale model of Eindhoven was calibrated and validated for dry weather including $\mathrm{C}$ and $\mathrm{N}$ removal (Nopens et al., 2010). This model is used as basis in the wastewater treatment plant modelling part of the current "Kallisto" project, which studies the integrated urban water system in the water cluster Eindhoven.

The innovation programme, entitled "Kallisto" (www.samenslimschoon.nl), aims at a smart improvement of the surface water quality of the river Dommel, by applying cost effective integrated system measures. A consortium was set-up bringing together Waterboards de Dommel, Brabantse Delta and Vallei\&Eem, the City of Eindhoven, the Dutch Water Research Foundation (STOWA) and knowledge institutes (Ghent University and Wageningen University). These parties collaborate to find 
ways to control storm water and waste water flows in the Eindhoven area to a higher extent, in order to meet the requirements of the European Union Water Framework Directive (WFD) more efficiently. After biological nutrient removal, the effluent of the treatment plant is discharged into the river Dommel. Rain water flow increases the treatment plant's influent by a factor of five, of which a part is treated in a parallel rain water treatment line present at the WWTP, when the plant's hydraulic capacity is exceeded. During intense storm water events, combined sewer overflow structures may discharge the surplus of storm water into the Dommel, negatively affecting the chemical and ecological quality of the river. Especially (toxic) ammonia peaks and oxygen deficiencies in the Dommel caused by overflow situations and effluent discharge during storm water events are targeted by the project. An innovative combination of monitoring, modelling and control of water flows and pollutions, construction of adequate technical measures is pursued to meet the goals of the project.

In order to efficiently realize appropriate investment and/or operational measures and efforts for the sake of a better surface water quality, a reliable dynamic WWTP model is needed to investigate the effects of proposed measures on the effluent quality and operation of the total system, either at the treatment plant level or elsewhere in the water treatment system. Possible measures may be directing higher hydraulic and pollution loads towards the WWTP or changes in operational strategies and investment measures like e.g. additional carbon dosage, additional aeration capacity or tertiary treatment options. This paper illustrates the progress made in modelling the WWTP using state-of-theart models for biological processes (ASM2d model modified by Gernaey and Jørgensen (2004)), chemical P-removal, and advanced, more accurate models for controllers and primary and secondary settling. The latter is done in conjunction with several on-line sensors in influent, in-process and effluent. In this way, a well-balanced dynamic model is being developed that is able to predict WWTP behaviour under various conditions. This is unlike typical projects where focus is only on one subprocess, typically the biological process.

\section{METHODS}

\section{Rationale}

It is our belief that a well-performing WWTP model should be well-balanced in structure. Usually, most efforts focus on the biological process model, ignoring the impact other processes might have (e.g. gas transfer, settling, mixing). This results in models that require significant calibration efforts. As models like ASM2d are over-parameterised and default model parameters have not been clearly defined, many researchers tend to misuse these degrees of freedom. This leads to mere fitting exercises and models with little predictive power. In the Kallisto project, however, more attention is paid to other submodels of the WWTP prior to extensively calibrating the biological process model. Therefore, the most relevant submodels that need further improvement were determined based on the current model and the goals of Kallisto (Fig. 1). Two main chunks of work can be distinguished: extensions/improvements needed in dry weather and extensions/improvements needed to enhance the predictive power in wet weather. Chemical phosphorus removal and implementation of the $\mathrm{NH}_{4}{ }^{+}$-DO cascade controller are the most important to improve the current dry weather model. In parallel, both primary and secondary settling models need further investigation. Once these submodels are improved, the attention can be directed to the biological P model, aeration model, mixing and hydraulic model. Moreover, several scenarios like the addition of external carbon sources can be evaluated and the effect on the operational cost, effluent quality and energy use can be compared. 


\section{Layout of the Eindhoven WWTP}

The Eindhoven wastewater treatment plant is located in the southeast of The Netherlands and treats the wastewater of 750.000 inhabitant equivalents (IE) with a design load of $136 \mathrm{~g} \mathrm{COD} \mathrm{day}^{-1} \mathrm{IE}^{-1}$. The incoming wastewater is treated in three parallel lines, each containing a primary settler, a biological tank and four secondary settlers. The plant is a modified UCT (University Cape Town) configuration (biological COD, $\mathrm{N}$ and $\mathrm{P}$ removal).

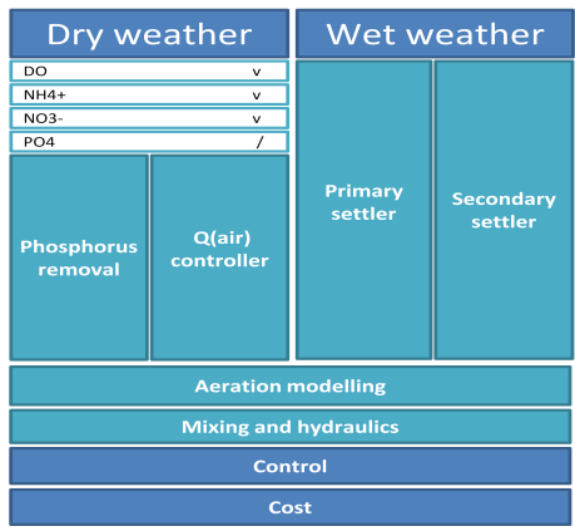

Figure 1 - Overall scheme of the integrated modelling approach to optimise the full-scale model of the Eindhoven WWTP. Current full-scale model of Eindhoven was calibrated and validated for dry weather including $\mathrm{C}$ and $\mathrm{N}$ removal (v) but not yet for phosphorus $(/)$

The circular anaerobic tank is a plug flow reactor, consisting of four compartments in series, with no aeration and minimal recycled nitrate. At the end of the fourth compartment, the mixed liquor enters the anoxic middle ring operated as a carousel. Subsequently, the mixed liquor enters the outer ring, which has membrane plate aerators in certain locations and is consequently a facultative aerobic/anoxic ring. Two zones of aerators can be distinguished: the 'summer package', which is constantly active and its airflow is controlled by a $\mathrm{NH}_{4}$-DO cascade controller and the 'winter package', which can be switched on during winter time or rain events to provide additional nitrification capacity. Finally, three recycles are active: one to recycle sludge from the anoxic middle ring to the anaerobic inner ring $(\mathrm{rec} A)$, a second one to recycle nitrate from the outer ring to the anoxic middle ring (recB) and a third one to recycle secondary sludge to the anoxic tank. A schematic of the biological tank is given in Fig. 2.

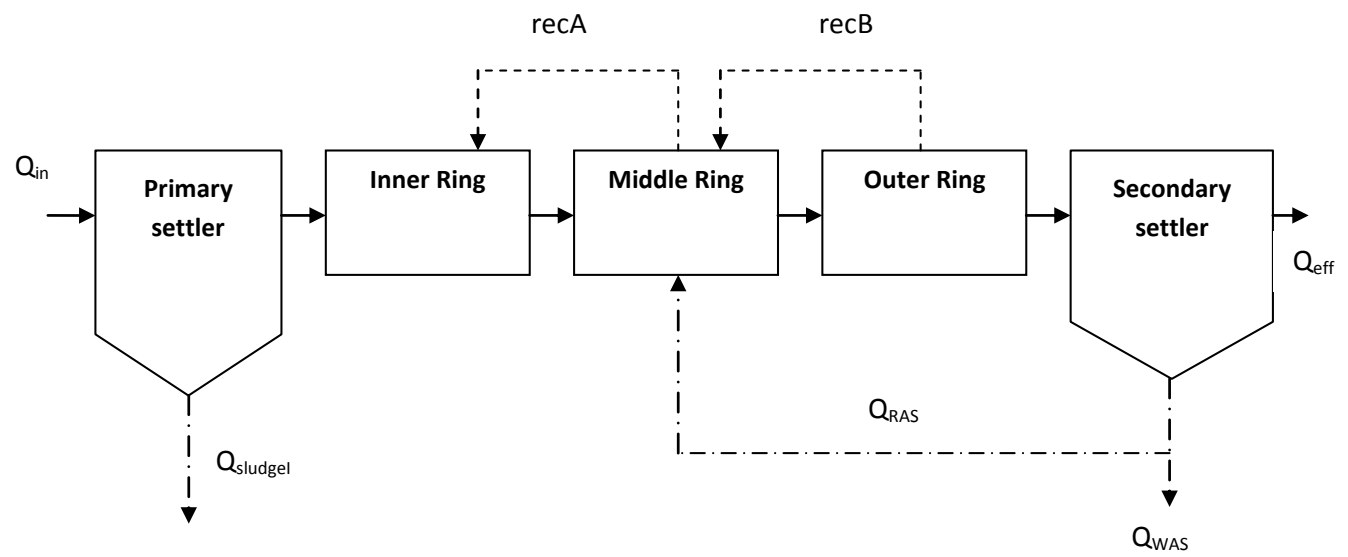

Figure 2 - Schematic overview of the Eindhoven WWTP configuration. The inner ring is the anaerobic zone, middle ring is the anoxic zone and outer ring is the facultative aerobic/anoxic zone. 


\section{Model of the Eindhoven WWTP}

The plant is modelled with the WEST simulator (http://www.mikebydhi.com, Denmark). Since bio-P is present in the plant, the ASM2d model modified by Gernaey and Jørgensen (2004) is used as biological model. The primary settler was originally modelled as a point settler with removal efficiency for TSS of $70 \%$ (based on measured data at the plant) and the secondary settler was modelled using the onedimensional 10-layer settling model (Takàcs et al., 1991).

\section{Data collection}

Off-line influent measurements of $\mathrm{NH}_{4}, \mathrm{COD}, \mathrm{BOD}$ and TSS are available from $24 \mathrm{~h}$ composite sampling as in most European plants. However, this poses a problem to perform dynamic simulation as the influent dynamics are poorly captured. However, in this case study, additional influent data consists of on-line measurements of the temperature of the incoming liquid $\left({ }^{\circ} \mathrm{C}\right)$, flow rate $\left(\mathrm{m}^{3} \mathrm{~d}^{-1}\right)$ and the concentrations $\left(\mathrm{mg} \mathrm{l}^{-1}\right)$ of total COD $\left(\mathrm{COD}_{\mathrm{t}}\right)$, soluble COD $\left(\mathrm{COD}_{\mathrm{s}}\right)$, total suspended solids $(\mathrm{TSS})$ (S::CAN, Austria), $\mathrm{NH}_{4}{ }^{+}$and $\mathrm{PO}_{4}{ }^{3-}$ (Hach Lange, Germany). The original data logged in the plant's SCADA system, has a one minute frequency. Ten-minute averages were calculated from the original one-minute data to reduce the measurement noise. Two ways were used to construct influent/input files for the model: based on on-line data (10 minute averages) or based on a correlation between flow and concentration (COD, TSS) obtained from a dry weather data period if high frequency on-line data were not available.

Process data consist of on-line measurements of dissolved oxygen concentration (DO) (mg $1^{-1}$ ) at the end of the summer and winter packages and $\mathrm{NH}_{4}{ }^{+}$and $\mathrm{NO}_{3}{ }^{-}$concentrations at the end of the summer package. The original data has a one-minute frequency, except for DO, which is measured every five minutes.

Control action data consists of one-minute data of airflow rate to the summer and winter packages $\left(\mathrm{m}^{3} \mathrm{~d}^{-1}\right)$, the flow rates $\left(\mathrm{m}^{3} \mathrm{~d}^{-1}\right)$ of both the sludge waste and the recycle flows and the TSS concentration of the sludge waste.

\section{RESULTS AND DISCUSSION}

As was shown in Fig 1, one of the strengths of the Kallisto project is that a multitude of research efforts are executed in parallel on multiple aspects of the WWTP model.

\section{Modelling the WWTP in dry weather conditions \\ Phosphorus removal modelling}

Since the current model is already able to predict COD and N very well without calibration, focus was turned to phosphorus predictions. The plant is designed for enhanced biological phosphorus removal (bio-P) combined with chemical $\mathrm{P}$ removal. It is unclear to what extent bio-P occurs at the moment. The addition of chemicals upfront the biological reactors is based on heuristic rules. The chemical dosage rate was manual, based on effluent $\mathrm{P}$ concentration. Metal $(\mathrm{Me})$ dosing ( $\mathrm{AlCl}$ solution, pure or residual product from a nearby industry) is set at maximum flow rate when $P_{\text {eff }}>1 \mathrm{mg} / \mathrm{l}$ and when the maximal storage capacity is reached. Metal dosing is stopped when $\mathrm{P}_{\text {eff }}<0.2 \mathrm{mg} / \mathrm{l}$.

Several existing chemical $\mathrm{P}$ removal models (de Haas, 2001) were evaluated taking into account available data. The most appropriate one, the model of Briggs, relates chemical $\mathrm{P}$ removal to metal (Fe or $\mathrm{Al}$ ) dosage empirically. This function is determined by the metal hydroxide and metal phosphate 
precipitation equilibria, limited by $\mathrm{pH}$ and becoming important at high metal to phosphate ratios. Figure 3 shows the predictions of the $\mathrm{PO}_{4}-\mathrm{P}$ concentration after chemical precipitation based on off-line $\mathrm{PO}_{4}-\mathrm{P}$ measurements before chemical addition (without calibration). The empirical model predictions are determined by the incoming phosphate concentration and the dosed amount of chemicals. In one of the five sampling data, where the $\mathrm{Me} / \mathrm{P}$ ratio is very high, $\mathrm{PO}_{4}-\mathrm{P}$ concentration is limited by chemical equilibrium. The chemical model was calibrated and used to model 1 year of off-line data (Figure 3). Because the prediction quality is very satisfying given the highly varying wastewater composition and the complex mechanisms involved in chemical $\mathrm{P}$ removal, a chemical dosing unit that determines $\mathrm{PO}_{4}$, the amount of precipitate (TSS) and the Al concentration after chemical dosing was implemented in WEST and can be included in the entire plant model.

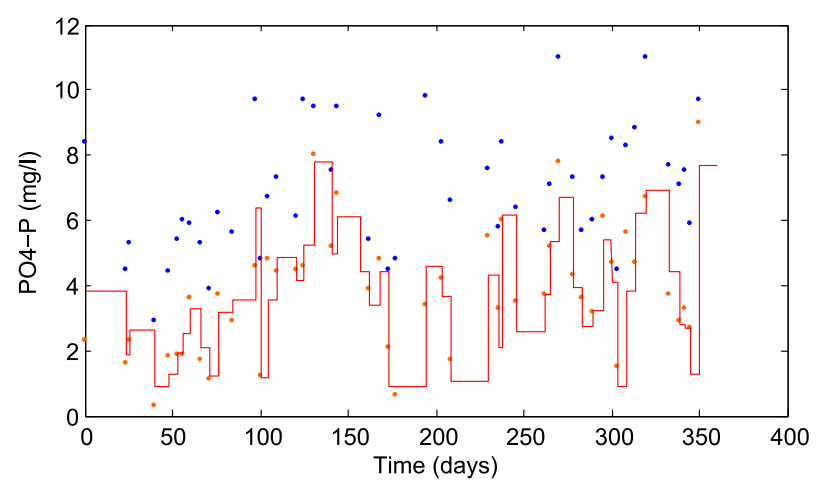

Figure 3 - Measured PO4-P concentration in the influent (blue dots) and measured (red dots) and predicted (red line) PO4-P concentration after chemical dosing

Since bio-P might occur in the plant and the intent to reduce chemical addition, the biological P-model needs to be investigated thoroughly. The ASM2d model modified by Gernaey and Jørgensen (2004) was used. These modifications were taken from the EAWAG-P module for ASM3 (Rieger, 2001) and include reduced decay rates for biomass (for $\mathrm{X}_{\mathrm{H}}, \mathrm{X}_{\mathrm{PAO}}, \mathrm{X}_{\mathrm{PP}}, \mathrm{X}_{\mathrm{PHA}}$ and $\mathrm{X}_{\mathrm{AUT}}$ ) under anoxic and anaerobic conditions. As stated before, in this approach, more attention is paid to other submodels of the WWTP prior to extensively calibrating the biological process model. However it could be that in later stages, default parameter values need to be slightly changed. Whereas default parameter values for ASM1 are based on very large data sets and should be fairly constant as it concerns sludge properties, this is not the case for ASM2d (Henze et al.,2000).

\section{Implementation of the NH4-DO cascade controller}

The modelling of the cascade ammonia-oxygen controller is important because supplied air flow rate data (logged in the SCADA system) is currently used as a model input, enabling the model to predict the WWTP's performance in the past, but does not allow future predictions. Furthermore, the modelling of the controller yields important information related to the performance of the implemented controller, its energy use, its ability to reduce ammonia peaks, etc. Figure 4 shows some preliminary results of the implemented incremental PID controllers. The master controller determines the DO setpoint based on the measured ammonia concentration in the aerated tank. Then the slave controller generates the needed air flow rate based on the DO setpoint and its measured value. 


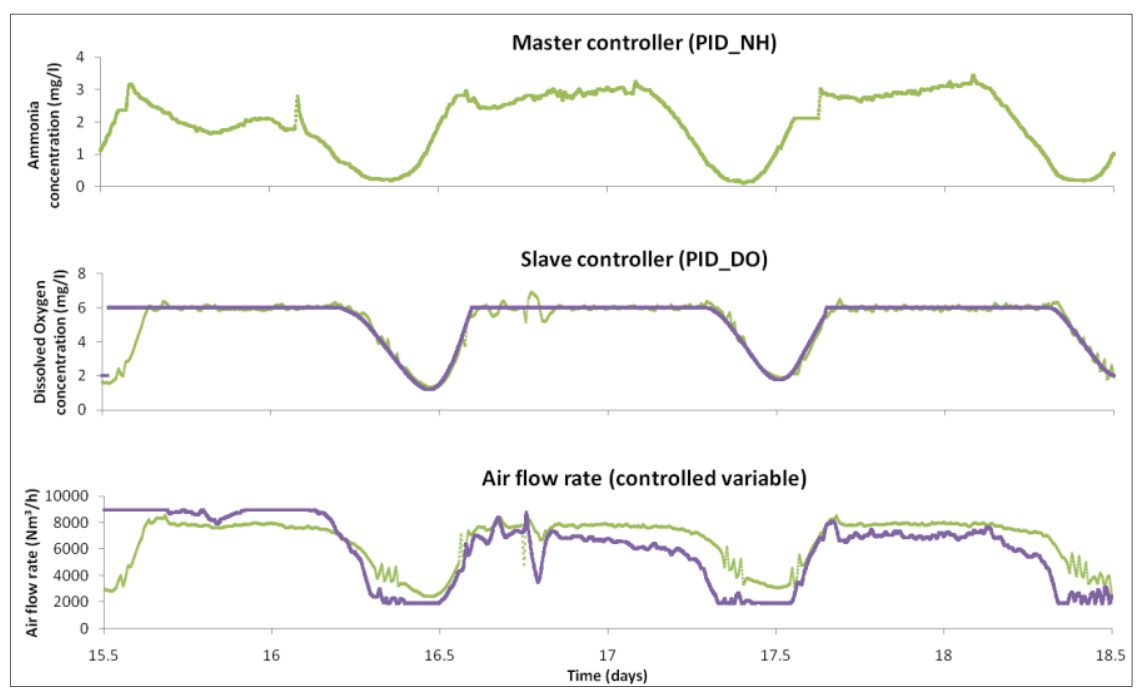

Figure 4 - Modelling results of the incremental PID controllers. Top: $\mathrm{NH}_{4}{ }^{+}(\mathrm{mg} / \mathrm{l})$. Middle: measured dissolved oxygen concentration. Bottom: airflow rate $\left(\mathrm{Nm}^{3} / \mathrm{h}\right)$. Green is measured, purple model prediction

Modelling the WWTP in wet weather conditions

Secondary settler

In wet weather, the current model is not able to predict the WWTPs performance as well as in dry weather. It was found that the secondary settling model (Takács et al., 1991) fails to correctly predict the return activated sludge concentration. This leads to severe faulty predictions of MLSS in the bioreactor as shown in Figure 5. This corresponds with recent findings in literature (Plosz et al., 2007; Bürger et al., 2011). Therefore, the Bürger model was adopted for the sludge removal system of the Eindhoven WWTP. Attention is currently focused on the proper calibration of this model. This is not only important with regard to model predictions in dry weather but also when considering measures to deliberately overload the WWTP in order to reduce the amount of wastewater discharged via combined sewer overflows (CSOs). A reliable settler model under this wide variety of extreme conditions is clearly necessary. Note that faulty MLVSS predictions will lead to a need for calibration of kinetics in the biological process model.

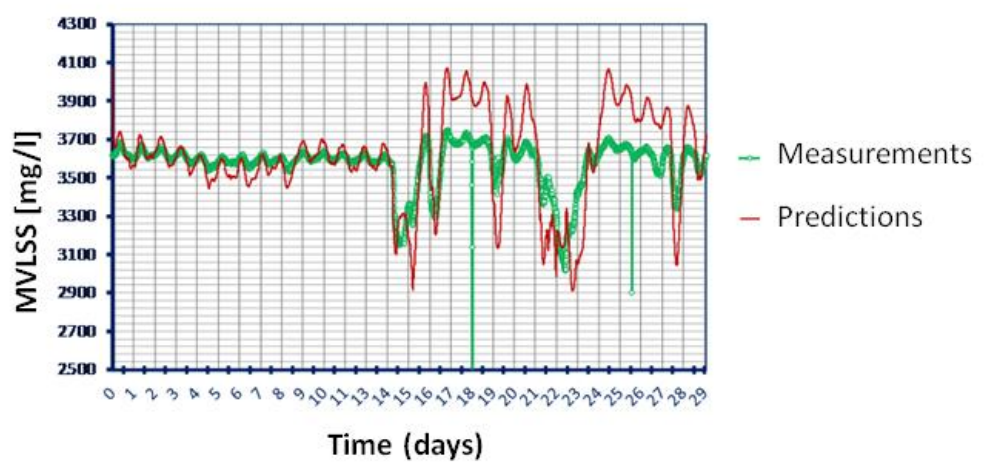

Figure 5 - MLSS measurements (mg/l) in the bioreactor (green) and model predictions (red) in June-July 2008. Rain events around day 14 and day 21. 


\section{Primary settler}

The primary settler is currently modelled using a simple point settler that splits the incoming flow in a settleable and non-settleable fraction. These fractions remain the same during the simulation, which is not reliable because the behaviour of the primary settler also changes in wet weather conditions, both with respect to influent composition due to dilution and fraction of TSS removed. The latter is included in the Tay model (Tay, 1982), which correlates settler removal efficiency with retention time (Equation 1). Retention time can be calculated from the volume and influent flow rate. Since no on-line efficiency data are available, $\mathrm{T}_{\mathrm{A}}$ was estimated based on typical data from Tchobanoglous et al. (2003).

$$
\frac{S_{0}-S}{S}=\frac{t_{r}}{T_{A}+t_{r}}
$$

where $\mathrm{S}_{0}$ is the suspended solids concentration in the influent of the primary settler $(\mathrm{mg} / \mathrm{l}), \mathrm{S}$ is the suspended solids concentration in the effluent of the primary settler $(\mathrm{mg} / \mathrm{L}), \mathrm{K}$ is a constant, $\mathrm{t}_{\mathrm{r}}$ is the actual retention time $(\mathrm{min})$ and $\mathrm{T}_{\mathrm{A}}$ is the half-removal time (min)

A combination of the improved primary and settling model give promising results. Both have an impact on the mixed liquor concentration in the activated sludge tank. In order to evaluate future scenarios reliably, it is necessary to perform a thorough calibration of both submodels. Preferably on separate data files that are directly linked to the specific units. This is currently under investigation.

\section{Integrated modelling of the WWTP}

Measures (scenario analysis)

The Kallisto project aims at comparing measures in the entire water treatment system (sewer and WWTP) in order to maximise the amount of treated water and minimise the pollution load to the river Dommel. Therefore, a truly integrated model (sewer, river and WWTP) is being developed.

Prior to finalising this integrated model, several measures at the level of the WWTP model can be tested. Although the current WWTP model is not yet sufficiently reliable for the whole scope of conditions we intend to, the model can already be used to qualitatively test some options. For example, as the current priority focus is on the reduction of ammonia peaks occurring during wet weather, the effect of extra aeration capacity was explored. Figure 6 shows that ammonia loads and concentrations reveal high peaks during storm events (days 14-30) compared to the dry weather conditions (day 1-13).

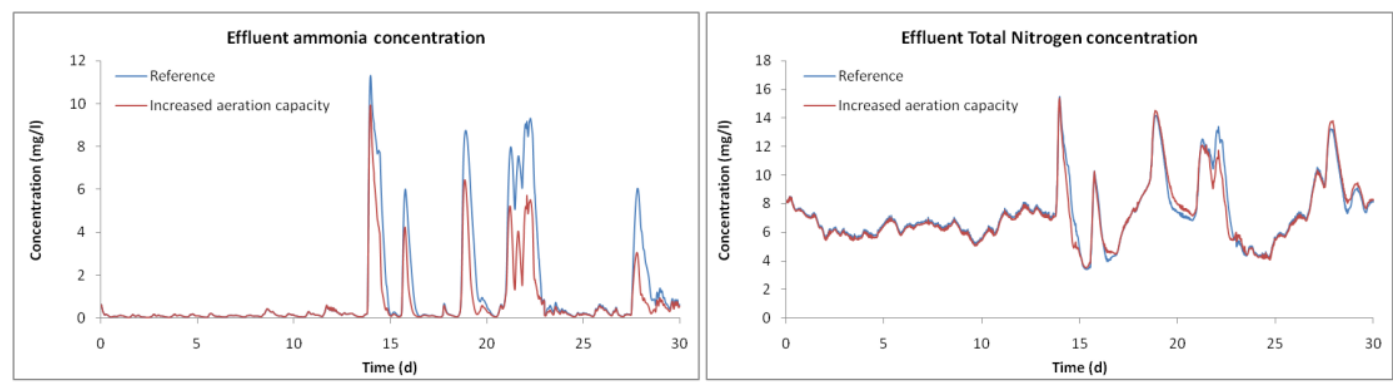

Figure 6 - Left: Predictions of ammonia (mg/l) and right: total nitrogen (mg/l) in the effluent in the reference case (blue) and with increased aeration capacity (red) in June-July 2008.

In the simulated scenario, additional aeration capacity is provided in the middle ring (anoxic zone) during storm events. As expected, this helps to a certain extent in lowering the ammonia peaks, but has no relevant impact on the effluent's total nitrogen given the plant's denitrification capacity is 
decreased. However, since total nitrogen is evaluated on a seasonal average basis, the simulated measure is still valuable.

\section{CONCLUSION}

In this paper, the Kallisto project and specifically the WWTP model development is illustrated. It can be regarded as quite exceptional since:

- Model development considers rigorous modeling of all subunits in the WWTP. This is not the case in most full-scale modeling studies as they tend to only focus on the biological process model in detail. More reliable submodels are often prevalent in literature, but not used.

- High quality and quantity data (1-10 minute) is collected at several locations to support the model development and calibration.

In order to use models in decision making, it is of major importance that the models reliably predict the process under all anticipated conditions. Therefore, the different submodels should be well-balanced and separately calibrated to avoid misfitting of other submodels. The latter is the case within the WWTP model but is also the case for the integrated water system's model. Indeed, the integrated model consists of the catchment, sewage, WWTP and river quality model, which all should be reliable under various conditions in order to make scientifically sound decisions. Once reliable integrated models are built, they will be an important tool in decision making.

\section{REFERENCES}

Bürger R., Diehl S. and Nopens I. (2011). A consistent modeling methodology for secondary settling tanks in wastewater treatment. Water Research, doi:10.1016/j.watres.2011.01.020

De Haas, D.W., Wentzel, M.C., and Ekama, G.A. (2001). The use of simultaneous chemical precipitation in modified activated sludge systems exhibiting biological excess phosphate removal: Part 6: Modelling of simultaneous chemical-biological P removal-review of existing models. Water S.A. 27(2): 135-150.

Gernaey K.V. and Jorgensen S.B. (2004). Benchmarking combined biological phosphorus and nitrogen removal wastewater treatment processes. Contr. Eng. Pract., 12, 357-373.

Henze M., Gujer W., Mino T. and van Loosdrecht M.C.M. (2000). Activated Sludge Models ASM1, ASM2, ASM2d and ASM3. IWA Scientific and Technical Report No. 9. IWA Publishing, London, UK.

Meijer S. C. F., van Loosdrecht M. C. M. and Heijnen J. J. (2002) Modelling the start-up of a full-scale biological nitrogen and phosphorus removing WWTP's. Water Res. 36, 4667-4682.

Nopens I., Plano S., Cierkens K., Benedetti L., van Nieuwenhuijzen A. and Weijers S. (2010). Impact of air flow rate and frequency of influent data on full-scale dynamic model calibration. In: Proceedings of WEFTEC 2010: 83rd annual technical exhibition and conference. October 2-6, 2010, New Orleans, LA, USA.

Plosz, B. G., Weiss, M., Printemps, C., Essemiani, K., \& Meinhold, J. (2007). One-dimensional modelling of the secondary clarifier-factors affecting simulation in the clarification zone and the assessment of the thickening flow dependence. Water Research, 41, 3359-3371.

Rieger, L., Koch, G., Kuhni, M., Gujer, W., \& Siegrist, H. (2001). The EAWAG Bio-P module for activated sludge model No. 3. Water Research, 35(16), 3887-3903.

Sin, G., De Pauw, D. J. W., Weijers, S., \& Vanrolleghem, P. A. (2008). An efficient approach to automate the manual trial and error calibration of activated sludge models. Biotechnology and Bioengineering, 100(3), 516-528.

STOWA (2001). Handboek biologische fosfaatverwijdering. STOWA, Utrecht, IV, $234 \mathrm{p}$

Takacs, I., Patry, G. G., \& Nolasco, D. (1991). A dynamic-model of the clarification thickening process. Water Research, 25(10), 1263-1271.

Tay, J.H. (1982). Development of a settling model for primary settling tanks. Water Research 16(9), 1413-1417.

Tchobanoglous, G., Burton, F., \& Stensel, H. (2003). Wastewater Engineering: Treatment and reuse, 4th Edition. Metcalf and Eddy.: New York, USA, McGraw-Hill. 